\title{
Developmental and Comparative Perspectives of Contagious Yawning
}

\author{
Atsushi Senju \\ Birkbeck College, University of London, London, UK
}

\begin{abstract}
Contagious yawning (i.e. yawning triggered by perceiving others' yawning) is a well-documented phenomenon, but the mechanism underlying it is still unclear. In this chapter, I review the current evidence about: (1) developmental studies with typically and atypically developing populations, and (2) comparative studies in non-human animals. Developmental studies have revealed that contagious yawning is disturbed in individuals with autism spectrum disorders, suggesting that contagious yawning may share a developmental basis with the capacity for theory of mind. Comparative studies have suggested that contagious yawning can be observed in non-primate species, such as domestic dogs. As dogs are known to have exceptional skills in communicating with humans, it has also been suggested that contagious yawning may be related to the capacity for social communication. These results from developmental and comparative studies are consistent with the claim that the mechanism underlying contagious yawning relates to the capacity for empathy.
\end{abstract}

Copyright $\odot 2010$ S. Karger AG, Basel

Contagious yawning (i.e. yawning triggered by perceiving others' yawning) is a well-documented phenomenon. Previous studies have consistently reported that, in a naturalistic or controlled experimental context, $45-60 \%$ of human adults yawn when they observe, hear or imagine others' yawning [1]. This is not due to common environmental factors between two yawners, such as temperature, lighting or the lack of oxygen, because pre-recorded yawning video clips and sounds can also induce contagious yawning [2-4]. Recently, this phenomenon has attracted a great deal of attention in the fields of developmental and comparative cognitive sciences. Apart from the intrinsic interest in this well-known but puzzling phenomenon, its attraction has been due to the fact that it is apparently empathetic: the observation of the emotional or physiological status of other individuals affects the emotional or physiological status of observer in a corresponding manner. Some researchers claim that the presence of contagious yawning in non-human animals is an index for their 
capacity for empathy $[5,6]$ and absence of contagious yawning in a developmental disorder or a psychiatric condition suggests a disturbance in their capacity for empathy $[7,8]$.

In this chapter, I review the current evidence from: (1) developmental studies with typically and atypically developing populations, and (2) comparative studies in non-human animals, discuss implications for the mechanism underlying contagious yawning, and raise several issues for future studies.

\section{Typical and Atypical Development of Contagious Yawning}

Apart from the initial case study by Piaget [9] - who, from observing his own daughter, reported that yawning in response to seeing a yawn started in the second year of life - Anderson and Meno [2] are the first and the only researchers to report a developmental trajectory of contagious yawning from an elaborate cross-sectional study. In their study, typically developing children aged 2-11 years old were exposed to a video presentation of yawning adults and a story including a yawning protagonist. The results revealed that some of the children aged 5 years or older showed contagious yawning in response to the video stimuli, and some of the children aged 6 years or older showed yawning in response to the yawning story. These results failed to replicate this early observation by Piaget [9], but the negative results reported for preschoolers should be treated with caution. For example, Anderson and Meno [2] discussed the possibility that familiarity with yawning adults may be relevant to the differences between these two studies.

In addition to the investigation of typical development, other scientists, including our group, have investigated the development of contagious yawning in children with autism spectrum disorders (ASD), who show atypical development in social interaction and communication [10]. Firstly, our research group has presented videotaped yawning as well as control mouth-opening actions to children with ASD as well as typically developing children between the ages of 7 and 15 years old [8]. Typically developing children showed more yawning in response to yawning movies than to control movies. By contrast, children with ASD showed equally frequent yawning in response to both yawning and control movies (fig. 1). These results replicated those of Anderson and Meno [2] in that typically developing children at the age of 7 years or older show contagious yawning. More importantly, this was the first study to demonstrate the absence of contagious yawning in children with ASD. Secondly, Giganti and Esposito Ziello [11] further explored the impact of the level of intellectual development upon the tendency to yawn contagion in children with ASD, by comparing children with ASD with higher and lower intellectual ability between the ages of 11 and 15 years old. They also used the auditory stimuli of yawning sounds, in addition to the visual stimuli of a yawning face, and also had the frequency of spontaneous yawning recorded by the parents. The results replicated the finding that both visual 

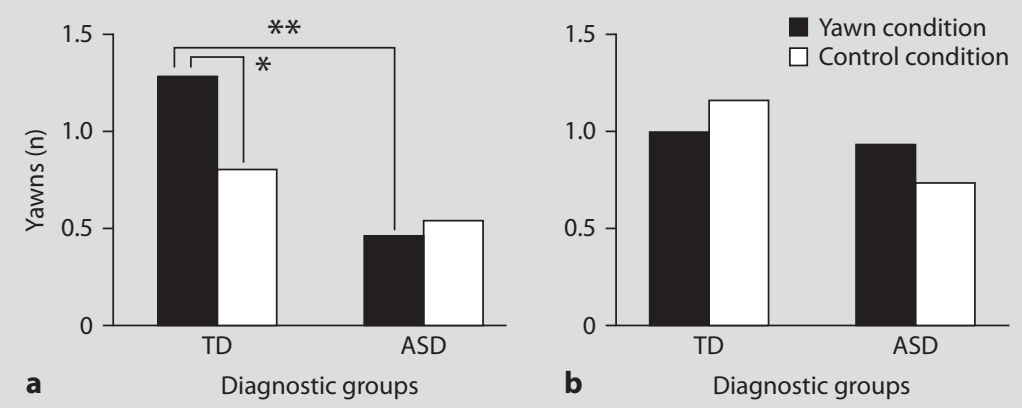

Fig. 1. Average frequency of yawns in participants during or after yawn and control conditions in Senju et al. [8] (a) and in Senju et al. [12] (b). TD = Typically developing children. ${ }^{* *} p<0.01 ;{ }^{*} p<0.05$. Reproduced with permission.

and auditory yawning stimuli elicited more yawning in typically developing children than in children with ASD. They did not find any effect of intellectual ability or group differences in the frequency of spontaneous yawning. These two studies suggest that children with ASD have an impairment in the mechanism relevant to the capacity for contagious yawning.

Thirdly, a recent study by the author's group [12] used a similar task used in Senju et al. [8] with an additional instruction to fixate on the eyes of the yawning face. The aim of this study was to test the hypothesis that an absence of contagious yawning in ASD is related to atypical social orienting, particularly the reduced spontaneous fixation on the eyes [13], because it has been reported that yawning eyes are as potent stimuli in eliciting yawning as the whole face, but a yawning mouth alone is not [14]. The results revealed that children with ASD yawned equally frequently in response to yawning stimuli as typically developing children once the additional instruction to fixate on the eyes was added. This is consistent with the hypothesis that reduced spontaneous fixations on the eyes may contribute to the absence of contagious yawning in ASD.

This research is consistent with the claim that the mechanism underlying contagious yawning relates to the capacity for theory of mind [4], the impairment of which is widely and consistently reported in individuals with ASD [15, 16]. However, the preliminary results of Senju et al. [12] may suggest that the absence of contagious yawning in ASD is mediated by the atypical pattern of spontaneous orienting to the eyes [13], not by the impairment in theory of mind per se. It is also possible that atypical social orienting is the common developmental basis of both atypical contagious yawning and the difficulty in theory of mind [17]. Further studies will be required to test the early development of contagious yawning in ASD, and its relation to the development of the social brain network. 

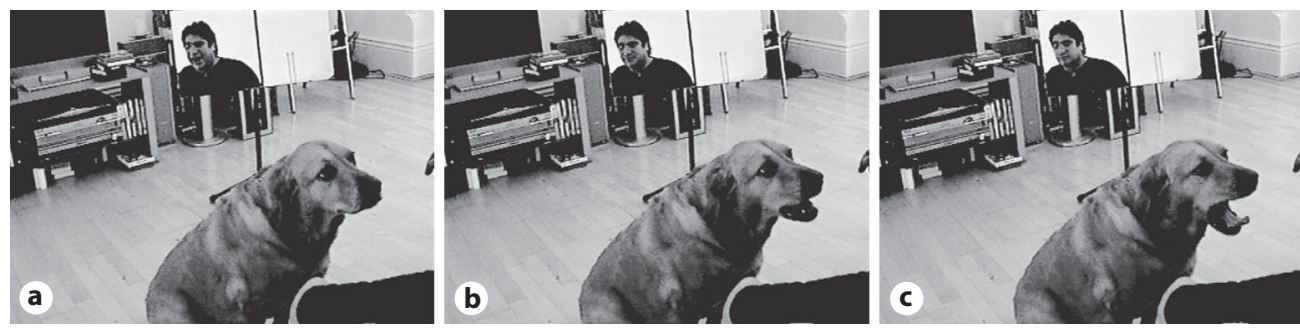

Fig. 2. A yawn response during the presentation of a human yawn. The experimenter's face can be seen at the top of each image, which was recorded in the mirror placed behind the dog. The dog observed the experimenter yawning (a), started yawning as the experimenter finished yawning (b) and then completed yawning (c). Reproduced with permission from Joly-Mascheroni et al. [6].

\section{Contagious Yawning in Non-Human Animals}

To the best of my knowledge, Anderson et al. [5] were the first to report quantitative data on contagious yawning in non-human animals. They presented yawning and control movies to 3 adult and 3 young chimpanzees (Pan troglodytes), and found a significant increase in the frequency of yawning in response to yawning movies in 2 adult chimpanzees. This result was replicated by a larger follow-up study [18]. In addition, Paukner and Anderson [19] reported that yawning movies elicit more yawning than control movies in stumptail macaques (Macaca arctoides). These studies suggest that the susceptibility to contagious yawning is not specific to humans, but could be shared with other non-human primate species.

A further question arises as to whether contagious yawning emerged during primate evolution, or is shared with an even wider range of animal species. To tackle this question, our research group conducted an experimental study to test whether domestic dogs (Canis familiaris) also show contagious yawning [6]. This study was motivated by several anecdotes from colleagues and other dog owners indicating their yawns elicit yawns from their dogs. Similar anecdotes can also be found in literature [20,21]. In our study, 29 dogs observed a live presentation of acted yawns by an experimenter, as well as the same human experimenter's non-yawning mouth movement. The experimenter called the dogs and/or presented a small piece of bait in front of the experimenter's face to make sure that the dogs made clear eye contact with the experimenter just before the experimenter presented a yawning or control mouth movement. Testing was conducted in places familiar to each dog, between 11 am and $4 \mathrm{pm}$ and after they had finished walking and had 1 of their 2 daily meals, to make sure that dogs attended the experiments in the least stressful way. In total, 21 out of 29 dogs yawned in response to the experimenter's yawns (fig. 2), but no dogs yawned in response to the control mouth movement produced by the same experimenter. These results clearly suggest that human yawns elicit a yawning response in dogs. Following our study, Harr et al. [22] presented video clips of humans and dogs 
yawning, as well as non-yawning mouth opening actions, to 15 dogs. Only 1 dog exhibited significantly more yawns in response to yawning video clips than to control video clips. It is not clear why Harr et al. [22] failed to replicate Joly-Mascheroni et al. [6], but it is likely that the way stimuli were presented contributed to the apparent discrepancy: it is possible that either the live presentation of stimuli, the social interaction between the yawning person and the dog, and/or establishment of eye contact before stimulus presentation is important for eliciting contagious yawning in dogs.

These results clearly demonstrated that human yawns elicit yawning in dogs, supporting the claim that the capacity for contagious yawning can be shared beyond the primate species. However, it is not necessarily warranted that the mechanism underlying contagious yawning is also shared among these species. For example, Paukner and Anderson [19] raised the possibility that apparently contagious yawning in stumptail macaques may be based on the heightened tension or stress induced by the observation of yawning, as yawning is a threatening signal in this species. Similarly, one could claim that part of the yawns observed in Joly-Mascheroni et al. [6] was a stress-related response induced by the yawning of a stranger, as some have argued that yawning in dogs is a response to acute stress [23]. However, more recent empirical studies [24, 25] have failed to confirm the relationship between stress and yawning, making this claim less convincing. Moreover, the presence of contagious yawning even when the potential 'tension yawns' were excluded from analyses [22] do not support this claim.

The current findings do not strictly support the relationship between theory of mind and contagious yawning, because there is no clear evidence supporting the presence of fully functional theory of mind in non-human animals, even in chimpanzees $[26,27]$. However, this does not deny the possibility that a precursor of theory of mind may relate to the capacity for contagious yawning in these species. For example, dogs are sensitive to human attention and communication cues [28, 29], and may even infer the knowledge status of humans [30].

\section{Conclusions and Future Directions}

In this chapter, I have reviewed developmental and comparative studies of contagious yawning. Even though the scarcity of existing studies prevents us from drawing any firm conclusions, the current findings tend to suggest that contagious yawning shares its mechanism with the capacity for theory of mind. In particular, a series of studies on children with autism highlighted that spontaneous orientation to socially relevant stimuli such as eyes may mediate contagious yawning in humans and possibly in nonhuman animals. These suggestions from preliminary findings merit further investigation of the relationship between the development of social cognition and contagious yawning. In this final section, I will summarize some possible directions for future research. 
Firstly, more studies are required to fully describe the developmental pathway of contagious yawning, as well as to assess the reasons behind the apparent contradiction between two of the existing developmental studies $[2,9]$ about the presence or absence of contagious yawning in children younger than 7 years. In addition, further studies are needed to test whether the absence of spontaneous contagious yawning is limited to children with autism, or can be observed in other developmental disorders that may or may not manifest impairments in social cognition.

Secondly, it is critical to test the prevalence of contagious yawning in non-human animals. As our recent study demonstrated the presence of contagious yawning in domestic dogs, it is possible that other non-primate species could also have the capacity for contagious yawning. Since our dog paper [6] was featured in the media, I have received numbers of anecdotes of yawn contagion from enthusiastic amateur naturalists and pet owners, including 4 independent reports about cats (Felis catus), a report about horses (Equus ferus caballus), an African grey parrot (Psittacus erithacus) and blackbirds (Turdus merula), as well as a report about a failed attempt with foxes (exact species not known). Of course it is likely that these anecdotes are based on the overinterpretation of incidental episodes, but I still think it is worth investigating. At the same time, it is also important to study to what extent contagious yawning in nonhuman animals shares the mechanism with human yawn contagion.

Growing number of new reports have begun to shed light on the mechanism underlying contagious yawning and its relations to other cognitive mechanisms. Further studies in the neural, developmental and evolutionary origin of contagious yawning will help us to better understand the mechanism underlying yawning, as well as the mechanism underlying social interaction and communication.

\section{Acknowledgments}

The author was supported by a research fellowship (RES-063-27-0207) from the UK Economic and Social Research Council.

\section{References}

1 Provine RR: Yawning as a stereotyped action pattern and releasing stimulus. Ethology 1986;72:448455.

2 Anderson JR, Meno P: Psychological influences on yawning in children. Curr Psychol Lett 2003;11 http://cpl.revues.org/index390.html.

- 3 Arnott SR, Singhal A, Goodale MA: An investigation of auditory contagious yawning. Cogn Affect Behav Neurosci 2009;9:335-342.
4 Platek SM, Critton SR, Myers TE, Gallup GG: Contagious yawning: the role of self-awareness and mental state attribution. Cogn Brain Res 2003; 17:223-227.

5 Anderson JR, Myowa-Yamakoshi M, Matsuzawa T: Contagious yawning in chimpanzees. Proc R Soc B Biol Sci 2004;271:S468-S470.

6 Joly-Mascheroni RM, Senju A, Shepherd AJ: Dogs catch human yawns. Biol Lett 2008;4:446-448. 
7 Haker H, Rössler W: Empathy in schizophrenia: impaired resonance. Eur Arch Psychiatry Clin Neurosci 2009;259:352-361.

$>8$ Senju A, Maeda M, Kikuchi Y, Hasegawa T, Tojo Y, Osanai $\mathrm{H}$ : Absence of contagious yawning in children with autism spectrum disorder. Biol Lett 2007; 3:706-708.

9 Piaget J: Play, Dreams and Imitation in Childhood. London, Routledge \& Kegan, 1951.

10 American Psychiatric Association: Diagnostic and Statistical Manual of Mental Disorders, ed 4 (text revision). Washington, APA, 2000.

11 Giganti F, Esposito Ziello M: Contagious and spontaneous yawning in autistic and typically developing children. Curr Psychol Lett 2009;25.

12 Senju A, Kikuchi Y, Akechi H, Hasegawa T, Tojo Y, Osanai H: Brief report: does eye contact induce contagious yawning in children with autism spectrum disorder? J Autism Dev Dis 2009;39:15981602.

13 Senju A, Johnson MH: Atypical eye contact in autism: models, mechanisms and development. Neurosci Biobehav Rev 2009;33:1204-1214.

14 Provine RR: Yawning and simulation science. Simulation 1989;53:193-194.

15 Baron-Cohen S, Leslie AM, Frith U: Does the autistic child have a 'theory of mind'? Cognition 1985;21:37-46.

16 Senju A, Southgate V, White S, Frith U: Mindblind eyes: an absence of spontaneous theory of mind in Asperger syndrome. Science 2009;325:883-885.

17 Senju A, Johnson MH: The eye contact effect: mechanisms and development. Trends Cogn Sci 2009;13: 127-134.

-18 Campbell MW, Carter JD, Proctor D, Eisenberg ML, de Waal FBM: Computer animations stimulate contagious yawning in chimpanzees. Proc Biol Sci 2009; 276:4255-4259.

19 Paukner A, Anderson JR: Video-induced yawning in stumptail macaques (Macaca arctoides). Biol Lett 2006;2:36-38.
20 Dureau de la Malle A: Mémoire sur le développement des facultés intellectuelles des animaux sauvages et domestiqués. Ann Sci Nat 1831;21: 388-419.

21 Rugaas T: On Talking Terms with Dogs: Calming Signals. Wenatchee, Dogwise, 1997.

22 Harr A, Gilbert V, Phillips K: Do dogs (Canis familiaris) show contagious yawning? Anim Cogn 2009; 12:833-837.

23 Beerda B, Schilder MBH, van Hooff JARAM, de Vries HW, Mol JA: Behavioural, saliva cortisol and heart rate responses to different types of stimuli in dogs. Appl Anim Behav Sci 1998;58:365-381.

24 Hennessy MB, Morris A, Linden F: Evaluation of the effects of a socialization program in a prison on behavior and pituitary-adrenal hormone levels of shelter dogs. Appl Anim Behav Sci 2006;99:157171.

25 Rooney NJ, Gaines SA, Bradshaw JWS: Behavioural and glucocorticoid responses of dogs (Canis familiaris) to kennelling: investigating mitigation of stress by prior habituation. Physiol Behav 2007;92: 847-854.

26 Call J, Tomasello M: Does the chimpanzee have a theory of mind? 30 years later. Trends Cogn Sci 2008;12:187-192.

27 Penn DC, Povinelli DJ: On the lack of evidence that non-human animals possess anything remotely resembling a 'theory of mind'. Philos Trans R Soc B Biol Sci 2007;362:731-744.

28 Hare B, Brown M, Williamson C, Tomasello M: The domestication of social cognition in dogs. Science 2002;298:1634-1636.

29 Topal J, Gergely G, Erdohegyi A, Csibra G, Miklosi A: Differential sensitivity to human communication in dogs, wolves, and human infants. Science 2009; 325:1269-1272.

30 Virányi Z, Topál J, Miklósi Á, Csányi V: A nonverbal test of knowledge attribution: a comparative study on dogs and children. Anim Cogn 2006;9:13-26.

Atsushi Senju

Centre for Brain and Cognitive Development, Birkbeck University of London, Malet Street London WC1E 7HX (UK)

Tel. +44 207631 6895, Fax +44 207631 6587, E-Mail a.senju@bbk.ac.uk 